\title{
DESAIN RANGKAIAN GATE-DRIVER UNTUK KONVERTER YANG BEKERJA DENGAN VOLTAGE MODE CONTROL
}

\author{
Fitriadi ${ }^{1^{*}}$ dan Muh. Imran Hamid ${ }^{2}$ \\ ${ }^{1}$ Program Studi Teknik Listrik, Jurusan Teknik Elektro, Politeknik Negeri Padang \\ ${ }^{2}$ Jurusan Teknik Elektro, Fakultas Teknik, Universitas Andalas \\ *Corresponding author, e-mail : fitriadichng@gmail.com
}

\begin{abstract}
Abstrak- Dalam berbagai peralatan elektronika daya, bagian gate-driver merupakan salah satu modul yang mempunyai peranan sangat penting dalam menentukan kualitas kerja konverter. Dalam paper ini diketengahkan sebuah desain modul gate-driver yang digunakan pada konverter yang berkerja dengan Voltage Mode Control (VMC). Rangkaian gate-driver dibangun menggunakan IC driver tipe MC33153 dengan isolasi cahaya HCPL4506. Suplai DC untuk input IC driver dan optocouplers didapatkan dari konverter DC/DC yang terisolasi dari sistem, sehingga keempat sinyal kontrol PWM yang hasilkan oleh rangkaian gate-driver juga terisolasi secara sistem. Pengujian yang telah dilakukan pada konverter yang beroperasi secara paralel pada input sebuah transformator paralelisasi menunjukkan fungsi-fungsi gatedriver beroperasi dengan baik. Secara umum, gate-driver yang dirancang prospektif digunakan dalam aplikasi-aplikasi lainnya.
\end{abstract}

Kata kunci : Gate-driver, Konverter, MC33153 dan HCPL4506, Voltage Mode Control (VMC)

\begin{abstract}
Gate-driver is part of power electronics equipments. This is one of important modules to determine the quality of converter. This paper discusses a design of gate-driver module in converter using Voltage Mode Control (VMC). Gate-driver circuit built using IC driver type MC33153 and light isolation HCPL4506. DC Supply for IC driver and optocouplers is got from DC/DC converter output which isolated from system. Then, four PWM signals control as output of gate-driver circuit isolated in system. Testing for converter which operated parallel in input transformator parallelizes shows the functions of gate-driver operating is good. In general speaking, the gate driver in prospective design is used in other applications.
\end{abstract}

Key words: Gate-driver, Konverter, MC33153 dan HCPL4506, Voltage Mode Control (VMC)

Copyright $\odot 2016$ JNTE. All rights reserved

\section{PENDAHULUAN}

Penggunaan teknologi konverter daya menjadi salah satu aspek yang sangat penting dalam mengoptimalkan pembangkitan energi terbarukan [1]. Hal ini ditemui misalnya pada solar sel yang membangkitkan tegangan DC, dalam hal ini, teknologi konverter mengubah tegangan DC hasil pembangkitan dari solar sel menjadi AC.

Sebuah konverter DC/AC dapat dikembangkan dari rangkaian kombinasi komponen semikonduktor jenis IGBT/ MOSFET. Konfigurasi topologi yang umum adalah full bridge sepeti diperlihatkan pada Gambar 1. Dalam rangkaian ini IGBT/ MOSFET berfungsi sebagai switch, jika di-input-kan sinyal kontrol PWM pada kaki gate 10-20 Volt DC [2]. Sinyal kontrol PWM yang dibangkitkan oleh mikrokontroler nilai tegangannya maksimum sebesar $5 \mathrm{~V}$ seperti yang ditunjukan pada Gambar 2. Untuk memperkuat sinyal output PWM dari mikrokontroler dapat digunakan sebuah rangkaian gate-driver, sehingga sinyal kontrol PWM tersebut mampu mengerakan IGBT/MOSFET [3] dan [5].

Ada banyak IC driver yang digunakan untuk mengerakan IGBT/MOSFET seperti IR2110, IR21362 dan EXB841, secara karakteristik semua IC driver tersebut masih memiliki kekurangan dalam memproteksi ganguan akibat dari proses switching dan menghasilkan arus balik pada saat switching karena suplai daya yang tidak terisolasi dari sistem [2].

Dalam paper ini, sebuah rangkaian gatedriver dibangun menggunakan IC driver tipe MC33153 dengan isolasi cahaya HCPL4506. Sehingga sinyal kontrol PWM output dari rangkaian gate-driver terisolasi dari sistem. Rangkaian gate-driver ini nantinya dapat 
digunakan dalam berbagai aplikasi-aplikasi lainnya. Misalnya untuk konverter DC/AC yang bekerja dengan metode phase shifted full bridge (PSFB) dengan teknik kontrol voltage mode control (VMC).

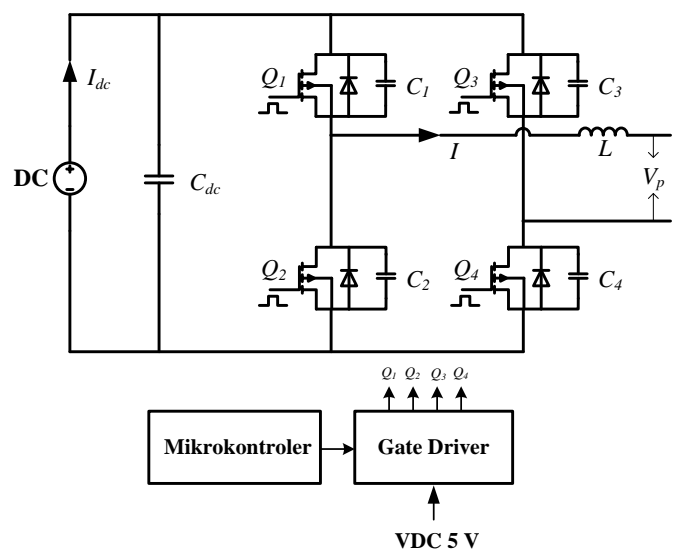

Gambar 1. Topologi full bridge konverter

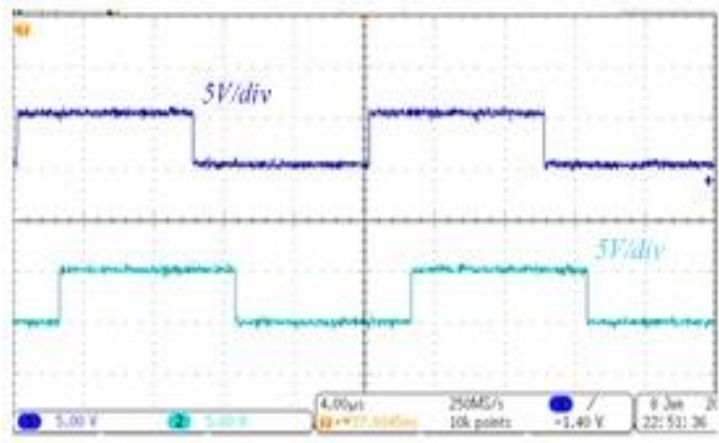

Gambar 2. Bentuk sinyal kontrol PWM output mikrokontroler

\section{TINJAUAN PUSTAKA}

Sebuah konverter DC/AC dengan topologi jembatan penuh dapat menghasilkan bentuk gelombang output persegi yang terkontrol dengan efisiensi tinggi sangat tergantung dari kualitas rangkaian gate-driver-nya [1] dan [6-9]. Menurut Zheng. W, dkk [2], beberapa kreteria yang dapat menetukan kualitas rangkaian gatedriver adalah sebagai berikut:

1. IC driver yang digunakan mampu memproteksi ganguan akibat dari proses switching.

2. Output sinyal kontrol PWM yang dihasilkan terisolasi dari sistem, sehingga arus balik pada saat switching tidak menimbulkan efek panas pada IGBT/MOSFET.

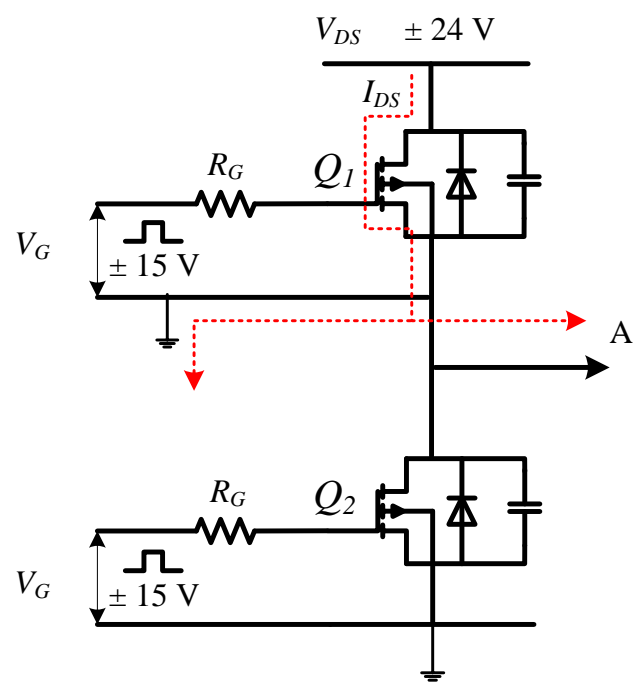

Gambar 3. Kondisi switching MOSFET dengan sinyal kontrol PWM yang terisolasi.

Dari Gambar 3 dapat dijelaskan, pada topologi setengah jembatan dengan dua buah MOSFET ( $Q 1$ dan $Q 2$ ) terhubung seri. Jika $Q 1$ ON arus $I_{\text {DS }}$ mengalir ke titik A dan nertral sinyal kontrol. Dalam kondisi ini, jika netral sinyal kontrol PWM saling terhubung arus $I_{\mathrm{DS}}$ juga mengalir ke nertral sumber hal ini menyebabkan terjadinya short circuit. Pada saat kondisi short circuit arus $I_{\mathrm{DS}}$ mengalir cukup besar karena tahanan drain sangat kecil sebesar $R_{\mathrm{D}}=0,1 \Omega$ dengan besar tegangan $V_{\mathrm{DS}}=24 \mathrm{~V}$, sehingga besarnya arus $I_{\mathrm{DS}}$ yang mengalir saat kondisi ON tersebut adalah sebesar.

$$
I_{D S}=\frac{V_{D S}}{R_{D}}=\frac{24}{0,1}=240 \mathrm{~A}
$$

Secara karakteristik (IRF530) batas maksimum arus $I_{\mathrm{DS}}$ yang diperbolehkan adalah 14 A pada temperatur $25^{\circ} \mathrm{C}$ [5]. Karena besarnya arus $I_{\mathrm{DS}}$ yang mengalir pada kondisi short circuit melebihi batas maksimum hal ini menyebabkan MOSFET panas dan rusak. Dengan mengembangkan rangkaian gate-driver yang terisolasi secara sistem dapat membuat semua nertral sinyal kontrol tidak saling terhubung.

\section{METODOLOGI PENELITIAN}

Rangkaian gate-driver untuk konverter DC/AC dikembangkan dari IC driver MC33153. Dimana secara karakteristik komponen ini didesain khusus untuk driver MOSFET/IGBT 
(Gambar 4) [2]. IC driver lainnya yang digunakan yaitu HCPL4506 yang berfungsi sebagai optocouplers. Cara kerja komponen ini berdasarkan transformasi cahaya, sehingga dapat mengisolasi sinyal input dari mikrokontroler terhadap sinyal output gatedriver seperti yang ditunjukan pada Gambar 5 .

Rangkaian gete-driver yang dapat menghasilkan empat buah sinyal kontrol PWM yang terisolasi dari sistem. Maksudnya suplai daya untuk kedua komponen IC driver berasal dari sumber DC tidak saling terhubung satu sama lainnya. Untuk mendapatkan suplai tegangan tersebut dibutuhkan beberapa konverter DC/DC yang dapat menguatkan tegangan DC 5 Volt menjadi $\pm 20 \mathrm{~V}$.

Dalam aplikasinya untuk rancangan satu unit konverter DC/DC menggunakan empat buah komponen switching jenis transistor. Transistor yang digunakan tipe NPN BC337 dua buah dan dua transistor tipe PNP BC327. Sinyal switching untuk transistor dengan frekuensi 1-2 $\mathrm{MHz}$ dihasilkan dari IC flip-flop HCT 7474. Untuk sinyal clock untuk IC flip-flop dihasilkan dari IC TTL 4700. Skema rangkaian dari konverter DC/DC dapat dilihat pada Gambar 6.

Tegangan AC 5V frekuensi tinggi yang dihasilkan kemudian diinputkan pada sisi primer transformator. Dalam hal ini sebuah transformator yang dapat bekerja pada frekuensi tinggi dikembangkan dari inti transformator jenis ferrite troidal. Kemudian kumparan transformator dililit sendiri dengan ratio perbandingan lilitan 3:20, agar dapat menghasilkan tegangan output pada sisi sekunder $\pm 20 \mathrm{~V}$. Dengan menggunakan dioda tipe IN4148 yang tersusun secara jembatan penuh, tegangan sisi sekunder dikonversi ke DC untuk suplai daya kedua komponen IC driver.

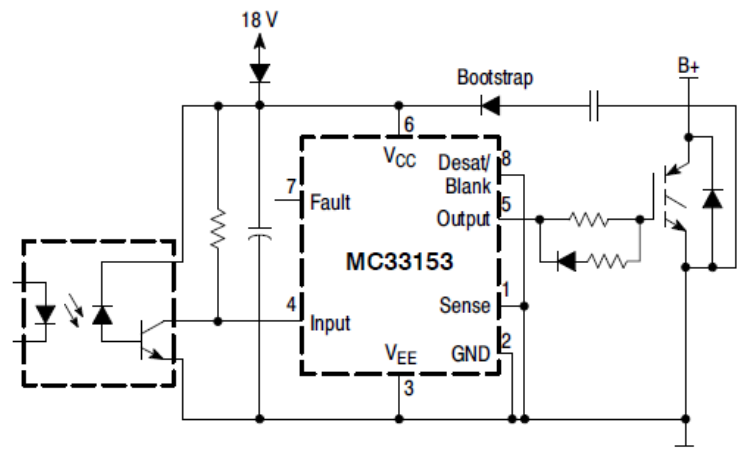

Gambar 4. Aplikasi dari IC MC33153 [2].

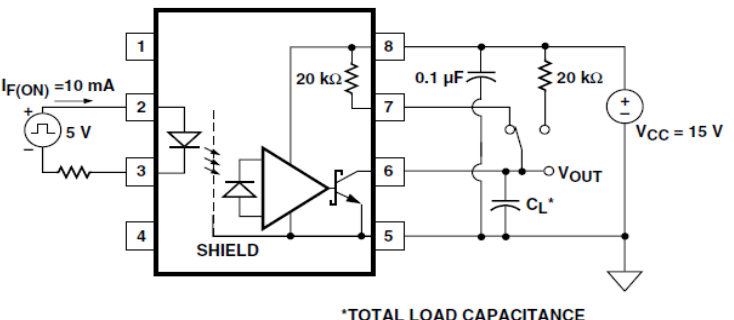

Gambar 5. Aplikasi dari IC HCPL 4506 [4].

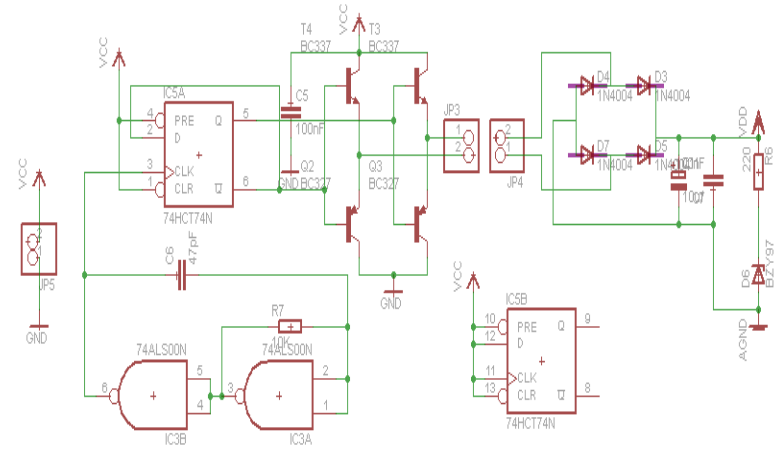

Gambar 6. Skematik rangkaian konverter DC/DC untuk IC driver

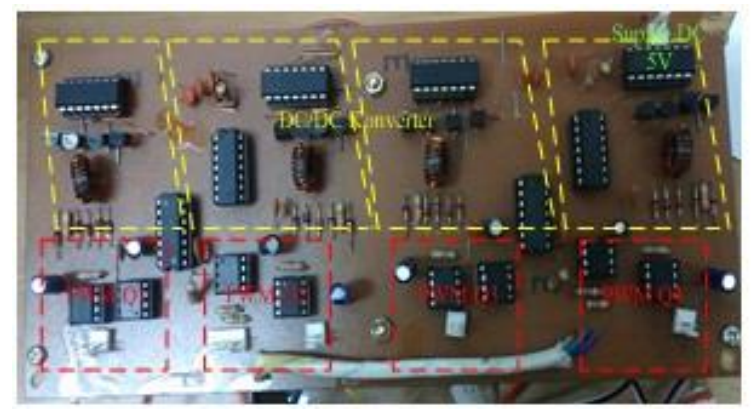

Gambar 7. Realisasi rangkaian gate-driver dengan empat buah sinyal kontrol PWM.

\section{HASIL DAN PEMBAHASAN}

\subsection{Pengujian Rangkaian Gate-driver}

Dalam pengujian ini, empat unit rangkaian koverter DC/DC diberi input tegangan $+5 \mathrm{~V}$ dari power supply catudaya DC. Tegangan output dari konverter DC/DC ini kemudian di-input-kan ke IC driver dengan besar tegangan suplai minimum $+15 \mathrm{~V}$ dan maksimum $+20 \mathrm{~V}$. Untuk itu rancangan transformator switching yang digunakan sangat menentukan sekali, sehingga rugi-rugi tegangan DC saat diinputkan ke IC driver kecil. Ukuran inti yang digunakan sebagai transformator switching adalah $10 \mathrm{~mm}$ untuk 
diameter luar $(o d)$ dan $6 \mathrm{~mm}$ untuk diameter dalam (id) dengan tebal $4 \mathrm{~mm}$ kemudian dililit dengan kawat tembaga diameter $0,40 \mathrm{~mm}$.

Sementara itu sinyal kontrol PWM yang diinput-kan pada rangkaian gate-driver dibangkitkan dari mikrokontroler Arduino Uno. Bentuk gelombang output dari rangkaian gatedriver di tunjukan pada Gambar 8.

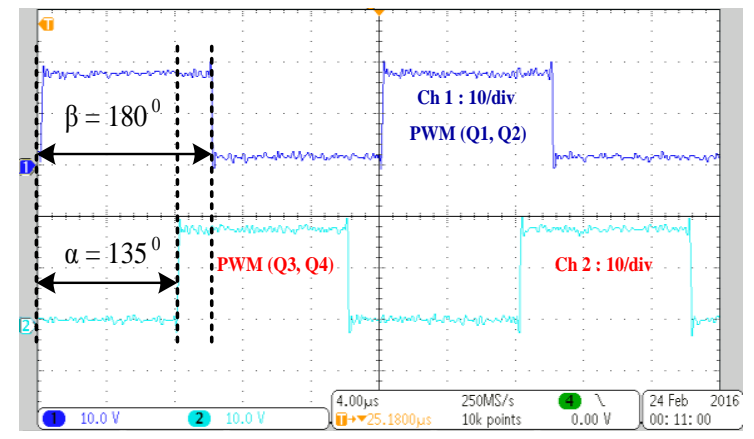

Gambar 8. Bentuk gelombang output sinyal PWM dari rangkaian gate-driver Ch 1: 10/div, Ch2 : 10/div, t : 4.00 $\mu \mathrm{s} / \mathrm{div}$

Pada Gambar 8 dapat dijelaskan sinyal kontrol PWM $Q 1, Q 2, Q 3$ dan $Q 4$ dengan besar amplitudo gelombang $\pm 18 \mathrm{~V}$ dengan satu siklus satu kali periode gelombang $5 \operatorname{div}(1 \operatorname{div}=4 \mu \mathrm{s})$, maka besar frekuensi switching-nya adalah:

$$
\begin{aligned}
& \mathrm{T}=5 \operatorname{div} \times 4,00 \mu \mathrm{s}=20 \mu \mathrm{s} \\
& F=\frac{1}{T}=\frac{1}{20 \mu \mathrm{s}}=50 \mathrm{kHz}
\end{aligned}
$$

Selanjutnya sinyal kontrol PWM ini di-inputkan ke kaki gate MOSFET IRF530 untuk menentukan nilai tahanan gate $\left(R_{\mathrm{G}}\right)$ yang optimum (Gambar 9). Nilai tahanan gate yang optimum ditentukan berdasarkan nilai delay time $\left(t_{\mathrm{d}}\right)$ yang paling kecil pada saat kondisi turn$O F F$.

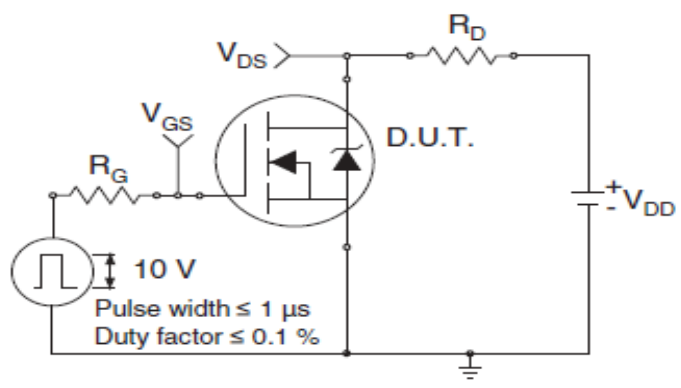

Gambar 9. Rangkaian pengujian switching MOSFET
Dalam pegujian ini, nilai tahanan gate $\left(R_{\mathrm{G}}\right)$ divariasikan dari $47 \Omega$ sampai dengan $1 \mathrm{k} \Omega$. Hasilnya menunjukan untuk nilai $R_{\mathrm{G}}$ yang menghasilkan nilai $t_{\mathrm{d}}$ yang kecil adalah $150 \Omega$ jika dibandingkan dengan nilai tahanan gate $\left(R_{\mathrm{G}}\right)$ $1 \mathrm{k} \Omega$. Bentuk gelombang sinyal switching hasil pengkurannya ditunjukan pada Gambar 10 a dan b.

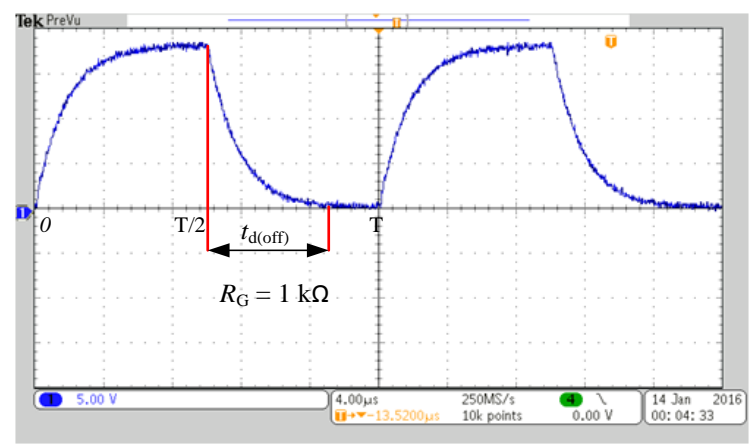

(a)

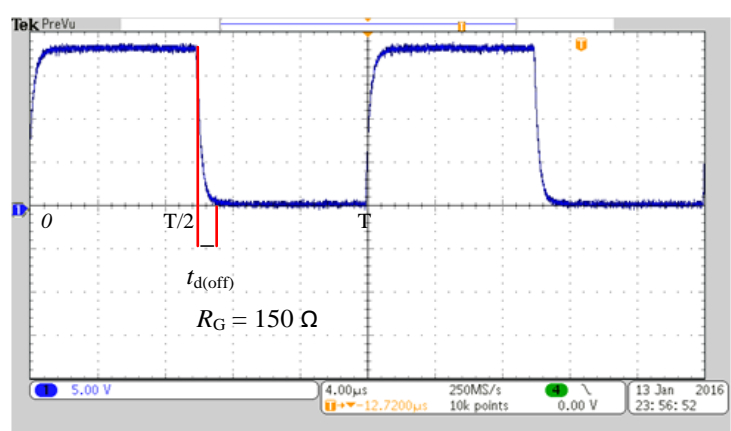

(b)

Gambar 10. Bentuk gelombang sinyal switching pada gate MOSFET: (a) $\mathrm{R}_{\mathrm{G}}=1 \mathrm{k} \Omega$ (b) $\mathrm{R}_{\mathrm{G}}=150 \Omega$

\subsection{Pengujian Rangkaian Gate-driver Pada Konverter DC/AC}

Pengujian kedua dilakukan sinyal kontrol PWM dari rangkaian gate-driver digunakan untuk masing-masing konverter DC/AC yang bekerja dengan metode phase shifted full bridge (PSFB) dengan teknik kontrol voltage mode control (VMC). Karena teknik kontrol ini dapat menghasilkan bentuk gelombang output persegi (square wave), tegangan output terkendali dan efisiensi tinggi pada saat konverter bekerja pada frekuensi tinggi. Keunggulan lainnya adalah dapat mereduksi rugi-rugi daya yang ditimbulkan pada kondisi switching serta dapat menghasilkan electromagnetic interference (EMI) dan ripple yang rendah [1] dan [6-9]. 
Dalam realisasinya seperti yang dikembangkan pada [8-9], sinyal kontrol PWM di-input-kan pada kaki gate $\operatorname{MOSFET}(Q 1, Q 2$, Q3 dan Q4) secara half bridge konverter leg 1 dan leg 2. Untuk leg $1(Q 1, Q 2)$ sinyal kontrol PWM dengan lebar turn-ON dan turn-OFF sebesar $\beta=180^{\circ}$ dengan duty cycle $50 \%$ pada frekuensi konstan di-input-kan pada $Q 1$, kemudian inverse dari sinyal kontrol PWM $Q 1$ diinputkan pada $Q 2$.

Untuk half bridge konverter berikutnya leg 2 $(Q 3, Q 4)$ sinyal kontrol PWM dengan duty cycle $50 \%$ pada frekuensi konstan didelai/shifted sudut fasa sebesar $\alpha^{0}$ terhadap sinyal kontrol PWM pada leg 1, delai/shifted sudut fasa ini agar terjadinya overlap pada kondisi turn-ON dalam waktu bersamaan secara diagonal. Konverter dengan teknik kontrol VMC ini semakin lama waktu overlap pada saat turn-ON semakin lama pula kondisi waktu tegangan diinput pada sisi primer kumparan transformator, dengan demikian semakin besar jumlah energi yang ditransfer ke sisi sekunder transformator [9].

Dalam pengujian ini, delai/shifted sudut fasa $\alpha^{0}$ sebesar $90^{\circ}$ dilakukan pada mikrokontroler. Pengamatan bentuk gelombang output konverter DC/AC menggunakan Osiloskop DIPO-3014 buatan Tektronix. Untuk mengukur kualitas dari rangkaian gate-driver, tegangan output dari konverter dihubungkan ke-sisi primer transformator frekuensi tinggi. Bentuk gelombang output konverter sebelum dan saat dihubungkan ke-sisi primer transformator ditunjukan pada Gambar 11.

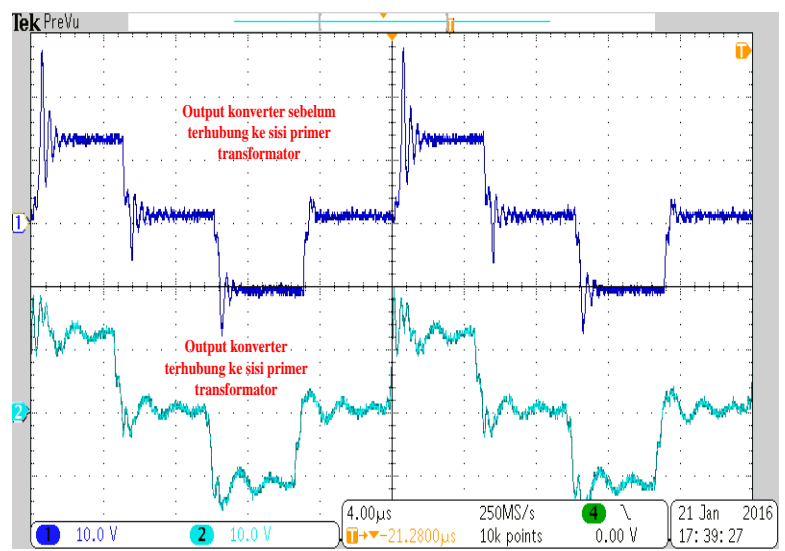

Gambar 11. Bentuk gelombang output konverter yang bekerja dengan voltage mode control (VMC)
Gambar 11 menunjukan bentuk gelombang output konverter sebelum terhubung ke sisi primer transformator spark wave kecil (hampir sempurna). Saat terhubung ke-sisi primer transformator ada spark wave. Hal ini disebabkan gelombang output dari konverter pada kondisi transisi switch dari turn-ON ke turn-OFF terjadinya turnish. Sebagai akibat driver pada kondisi switching yang tidak sempurna. Sedangkan hasil pengujian paralelisasi dua konverter pada sisi input transformator ditunjukan pada Gambar 12.

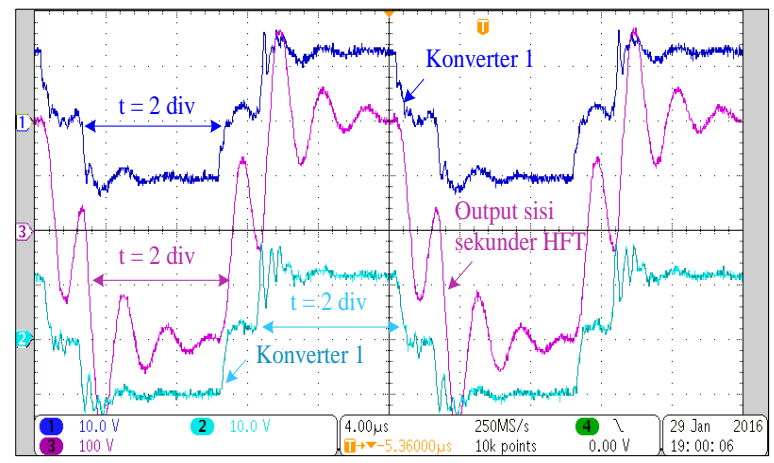

Gambar 12. Bentuk gelombang output konverter DC/AC yang beroperasi secara paralel pada sisi input transformator, Ch 1: 10/div, Ch2 : 100/div, t : $4.00 \mu \mathrm{s} / \mathrm{div}$

Pada gambar 12, terlihat gelombang output dari masing-masing konverter DC/AC dengan mengunakan rangkaian gate-driver dapat menjadi sefasa. Sehingga paralelisasi konverter sisi input transformator dapat dilakukan.

\section{KESIMPULAN}

Dalam paper ini telah dipaparkan sebuah desain modul gate driver menggunakan IC driver tipe MC33153 yang diperuntukkan mengendalikan operasi komponen switch dalam suatu konverter daya. Desain yang diketengahkan menekankan aspek isolasi antara blok kontrol dan blok daya pada konverter, dan pada desain ini aspek isolasi ini diimplementasikan menggunakan HCPL 4506. Power supply bagi modul didesain berupa konverter DC/DC yang terisolasi dari rangkaian daya konverter. Oprasi gate-driver telah dicobakan pada konverter paralelisasi dan menunjukan perporma yang memuaskan. 


\section{DAFTAR PUSTAKA}

[1] Irawan. J. A., Firmansyah. E., Wijaya. F. D.; Perancangan Transformator Frekuensi Tinggi untuk Konverter DCDC Full bridge Phase-Shifted $200 \mathrm{~W}$. Seminar Nasional Aplikasi Teknologi Informasi (SNATI) 2013 Yogyakarta, 15 Juni 2013.

[2] Zheng. W., Meiying. Q.; The Application of IGBT Driver MC33153. IEEE. 978-14244- 7618-3. 2010

[3] Tarmizi, Muyassar.; Rancang Bangun Inverter SVM Berbasis Mikrokontroler PIC 18F4431untuk Sistem VSD. Jurnal Nasional Teknik Elektro. Vol: 2 No. 1 Maret 2013.

[4] Avago Technologies.; Data sheet HCPL 4506. www.avagotech.com

[5] Vishay Siliconix.; Data sheet Power MOSFET IRF 530.

[6] Puyal. D., Barragán. L. A., Acero. J.; An FPGA-Based Digital Modulator for Fullor Half-Bridge Inverter Control. IEEE Transactions On Power Electronics, Vol. 21, No. 5, September 2006.

[7] Arya. P. S., Chithra. R.; Phase Shifted Full Bridge DC-DC Converter. International Research Journal of Engineering and Technology (IRJET). Volume: 02 Issue: 04. July-2015.

[8] Texas Instruments.; Phase-Shifted Full Bridge DC/DC Power Converter Design Guide. May 2014. www.ti.com

[9] Nene. H.; Implementing advanced control strategies for phase-shifted, fullbridge DC/Dcconverters using MCUs (Part lof 2). Systems and Applications, for Texas Instruments Incorporated. 2000

\section{Biodata Penulis}

Fitriadi, lahir di Padang tanggal 14 Maret 1982, mahasiswa Pasca Sarjana Jurusan Teknik Elektro Fakultas Teknik Universitas Andalas Padang, Fungsional Pranata Laboratorium Pendidikan (PLP) Ahli Pertama di Laboratorium Sistem Distribusi dan Proteksi Jurusan Teknik Elektro Politeknik Negeri Padang. 